
\title{
$\begin{array}{ll}\text { Research Square } & \begin{array}{l}\text { Preprints are preliminary reports that have not undergone peer review. } \\ \text { They should not be considered conclusive, used to inform clinical practice, } \\ \text { or referenced by the media as validated information. }\end{array}\end{array}$
}

\section{Stability and clinical outcomes of a new one piece toric intraocular lens with anchor-wing haptics}

lichiro Sugita ( $\nabla$ iichiro@sugita.or.jp )

MedStar Harbor Hospital https://orcid.org/0000-0002-2311-2203

\section{Tomoichiro Ogawa}

Miyamaedaira Ogawa Eye Clinic

Kazuo Ichikawa

Chukyo Eye Clinic

Takahide Okita

Sugita Eye Hospital

Kazuno Negishi

Keio University School of Medicine

\section{Tadashi Nakano}

The Jikei University School of Medicine

Hiroshi Tsuneoka

The Jikei University School of Medicine

\section{Research article}

Keywords: toric intraocular lens, intraocular lens, corneal astigmatism, cataract, cataract surgery, rotational stability, anchor-wing haptics

Posted Date: November 11th, 2020

DOI: https://doi.org/10.21203/rs.3.rs-55494/v2

License: @ (i) This work is licensed under a Creative Commons Attribution 4.0 International License. Read Full License 


\section{Abstract}

Background: To evaluate the safety and efficacy of a new toric intraocular lens (IOL) with anchor-wing haptics.

Methods: The new toric IOL with anchor-wing haptics (NS60YT, NIDEK Co., Ltd.) was implanted in eligible patients with age-related cataracts with preoperative corneal astigmatism of $1.0 \mathrm{D}$ or greater at a university hospital and two private hospitals in Japan. The following IOL cylinder powers were evaluated: $1.50 \mathrm{D}$ (NS60YT3), 2.25 D (NS60YT4), 3.00 D (NS60YT5) and 4.50 D (NS60YT7). All patients were assessed out to 12 months postoperatively. The primary endpoint was uncorrected visual acuity (UCVA) with spherical addition at 6 months postoperatively, and the primary analysis calculated the proportion of eyes with UCVA with spherical addition of $0.1 \log M A R$ or better. The magnitude of rotation was compared to the intended axis of $\mathrm{IOL}$ implantation at each postoperative examination. Adverse events were evaluated for the safety analysis.

Results: This study enrolled 64 eyes of 53 patients. At 6 months postoperatively, for all IOL powers, UCVA with spherical addition of 0.1 logMAR or better was achieved in $90 \%$ [95\% confidence interval (CI): 80-96] of eyes. The mean IOL rotation was $5.3 \pm 4.3^{\circ}$ at 12 months postoperatively. The mean magnitude of rotation ranged from $1.9^{\circ}$ to $2.5^{\circ}$ between each postoperative examination from 1 day to 12 months. There were no visionthreatening intraoperative or postoperative complications for the duration of the study.

Conclusions: The NS60YT IOL remained stable after implantation and was efficacious for treating $1.00 \mathrm{D}$ or greater astigmatism in patients with senile cataracts.

Trial registration: This study was registered at ClinicalTrials.gov (NCT03242486) on August 8, 2017 Retrospectively registered. (https://clinicaltrials.gov/ct2/show/NCT03242486)

\section{Background}

The reduction of astigmatism during cataract surgery is an important factor in visual function and postoperative patient satisfaction. Approximately $35 \%$ of patients with cataract have preoperative corneal astigmatism of $1.0 \mathrm{D}$ or greater and approximately $20 \%$ have $1.5 \mathrm{D}$ or greater astigmatism [1-4]. Residual astigmatism after phacoemulsification and intraocular lens (IOL) implantation is a significant cause of suboptimal vision, increased spectacle dependence or patient dissatisfaction $[5,6]$. There are a variety of methods currently used for treating cataracts with corneal astigmatism, including but not limited to, implantation of supplementary sulcus-fixated IOLs, implantation of pinhole IOLs, or laser refractive surgery for a corneal "touch-up". The advantages of toric IOL implantation include a wider range of correction and the use of one procedure to simultaneously correct the refractive error, reducing the burden on the patient and the surgeon [7].

The Aktis toric (Model NS60YT; Nidek Co., Ltd.) is a newly developed IOL that is based on the existing monofocal Nex-Acri® AA 1P IOL platform (Nidek Co., Ltd.). Rotational stability for this IOL is maintained by anchor-wing haptics. In this prospective, multicenter study, we present the stability and clinical outcomes of NS60YT implantation for the correction of moderate to high astigmatism. 


\section{Methods}

This single-arm, open-label, multicenter, prospective clinical study evaluated implantation of the NS60YT in patients with age-related cataracts at a university hospital and two private hospitals in Japan. This study was approved by the Jikei University Hospital Institutional Review Board for Medical Devices, the Sugita Eye Hospital Institutional Review Board, and the Joint Institutional Review Board of the hospitals. The study adhered to the Declaration of Helsinki and the Japanese Ministerial Ordinance on Good Clinical Practice for Medical Devices (GCP). This manuscript adheres to the CONSORT guidelines. The study protocol is available at https://clinicaltrials.gov. Written informed consent was obtained from all patients before participation. The study period was from December 2014 to November 2017. The duration of follow up was 12 months postoperatively.

\section{Intraocular lens}

The NS60YT is a single-piece toric IOL based on the Nex-Acri® series (Nidek Co., Ltd.) (Fig. 1). The optical diameter is $6.0 \mathrm{~mm}$ and the overall diameter is $13.0 \mathrm{~mm}$ including the anchor-wing haptics. The lens is a biconvex lens and the rear surface is aspheric $(-0.15 \mu \mathrm{m})$. The cylindrical power is placed on the front of the lens for the correction of corneal astigmatism. The IOL consists of hydrophobic soft acrylic resin with an ultraviolet absorber and proprietary material to enhance compatibility with the injector. The lens has two dots on either side of the optic periphery, indicating the flattest meridian for marking the cylinder axis. This study evaluated 4 different toric IOL powers as follows: 1.50 D, 2.25 D, 3.00 D and 4.50 D (Table 1).

Table 1 Cylindrical power of each model of the NS60YT intraocular lens.

\begin{tabular}{|l|r|r|}
\hline Model name & IOL surface power (D) & Power at the Corneal Plane (D) \\
\hline NS60YT3 & 1.50 & 1.05 \\
\hline NS60YT4 & 2.25 & 1.57 \\
\hline NS60YT5 & 3.00 & 2.08 \\
\hline NS60YT7 & 4.50 & 3.11 \\
\hline
\end{tabular}

\section{Patients}

Patients were included if they were over 40 years old with age-related cataracts in one or both eyes with a pupil diameter of $5.0 \mathrm{~mm}$ or larger at mydriasis and had $1.0 \mathrm{D}$ or greater preoperative corneal astigmatism. Other inclusion criteria were, a predicted postoperative astigmatism less than $0.5 \mathrm{D}$, and the predicted postoperative uncorrected visual acuity (UCVA) with spherical addition of 0.1 logMAR or better. "UCVA with spherical addition" is visual acuity measured under conditions where a spherical trial lens is added to correct the postoperative spherical refractive error determined before surgery for each patient. For example, when the target spherical refractive error is $-1.5 \mathrm{D}$ preoperatively, the visual acuity value measured with a $-1.5 \mathrm{D}$ spherical trial lens added postoperatively, is considered the "UCVA with spherical addition".

Patients were excluded if they had irregular corneal astigmatism, long axial length ( $28 \mathrm{~mm}$ or longer), and other diseases or complications that might affect the efficacy and safety of IOL implantation.

\section{Preoperative examination}


Within 60 days prior to surgery, the patient underwent thorough ophthalmic examinations including, slit lamp microscopy, corneal topography (OPD-Scan® III; Nidek Co., Ltd.) for measurement of corneal astigmatism, measurement of pupil diameter, tonometry, fundus examination, and axial length measurement (IOLMaster $\AA$; Carl Zeiss Meditec AG).

\section{Calculation of intraocular lens power using a toric calculator}

The IOL spherical power was selected by the surgeon based on the desired postoperative refractive error for each patient using the biometry values. The SRK/T formula was used for all eyes. The A-constants (119.7) were adjusted for each clinical site based on the constant for the Nex-Acri® AA 1P that is the same shape as NS60YT. The Nidek Toric Calculator For Clinical Trials was used to select cylinder power and to calculate the angle of implantation. Data entry of the preoperative corneal astigmatism, the surgically induced astigmatism for each surgeon, and the location of the incision allows calculation of the predicted postoperative corneal astigmatism, the IOL implantation axis, and the predicted postoperative residual astigmatism for each model. Based on these variables, the surgeons selected the optimum IOL model that predicted the lowest postoperative astigmatism.

\section{Surgery}

Once the axis of implantation was verified with topographic data just prior to surgery, the patient was seated at a slit lamp and the surgeon used a gentian violet pen to mark the 3-o'clock, 6-o'clock and 9-o'clock positions. Intraoperatively, once the patient is supine and just prior to IOL implantation, the absence of head tilt is verified, and the gentian violet marks are used with a protracting device to find the target meridian. All surgeries were performed with topical anesthesia using a sterile technique as follows: a 2.2 to $2.5 \mathrm{~mm}$ corneal, scleral or sclerocorneal incision was created and the cataractous lens was removed by phacoemulsification and aspiration, and an IOL was inserted into the lens capsule so that the toric marks on the IOL were aligned with the marks for axis alignment. An injector (Nex-IJ; Nidek Co., Ltd.) was used for IOL insertion. In patients scheduled for bilateral surgery, the fellow eye underwent surgery after the initial eye was evaluated at 1 week postoperatively and there were no complications.

\section{Postoperative examination}

Postoperative examinations were performed the day after surgery (1-2 days), 1 week after surgery (7-14 days), 1 month after surgery (30-60 days), 3 months after surgery (90-150 days), 6 months after surgery (180-240 days), and 12 months after surgery (360-420 days). Postoperative examinations included slit lamp microscopy, tonometry, fundus examination, measurements of corneal curvature with corneal topography, UCVA, UCVA with spherical addition, sphere-corrected visual acuity (VA), best corrected distance visual acuity (BCVA), IOL axis, and a patient questionnaire (only at 6 months postoperatively). Sphere-corrected VA is the visual acuity when only the sphere was corrected from the UCVA with spherical addition based on the postoperative spherical error.

The IOL axis was measured manually using slit lamp photography or from images obtained with anterior segment imaging devices (KATS-1000; Konan medical Co., Ltd. and Casia; Tomey Corp.). The patient was seated at the slit lamp and the correct head position (no tilt) was verified prior to acquiring photographs. 
Deviation between the corneal astigmatic axis and the axis marks on the IOL was determined by using a protractor. The image was regarded as horizontal, and the angle was measured between the horizontal line and the toric mark. The patient questionnaire classified current vision into five rankings as follows: "very satisfied", "satisfied", "neither satisfied nor dissatisfied", "dissatisfied", and "very dissatisfied".

Data were collected on all postoperative adverse events irrespective of causality. The following adverse events that may occur after cataract surgery were summarized as anticipated adverse events at every postoperative examination: secondary cataract (requiring posterior capsulotomy), macular degeneration, macular edema, hypopyon, infectious and noninfectious endophthalmitis, pupil block, retinal detachment, corneal edema, iritis, increased intraocular pressure (IOP), and IOL dislocation. Increased IOP was defined as $23 \mathrm{~mm} \mathrm{Hg}$ or higher and an increase of $5 \mathrm{~mm} \mathrm{Hg}$ or higher compared to the preoperative IOP.

\section{Statistical analysis}

We used previous studies of toric IOLs that targetted emmetropia as the historical control to determine the number of cases that achieved a postoperative UCVA of 0.1 logMAR or better [8-10]. The analysis indicated 47 eyes were required for NS60YT3, NS60YT4, NS60YT5 (significance level $a=0.05$, power $1-\beta=0.80$ ), based on the threshold response rate $(\pi 0) 0.5$ and the expected response rate $(\pi 1) 0.7$. For high astigmatism (NS60YT7), data were collected on only 5 eyes due to the lack of appropriate patients.

The primary endpoint was the UCVA with spherical addition 6 months after surgery, and the primary analysis calculated the proportion of UCVA with spherical addition of 0.1 logMAR or better and a $95 \%$ confidence interval (CI). The Clopper-Pearson method was used to calculate $95 \%$ Cls. Secondary endpoints included UCVA, sphere-corrected VA, BCVA, refractive cylinder correction, and the magnitude of IOL rotation. Visual

acuity was recorded in decimal notation at all sites, however for statistical analysis and consistency, all values were reported in logMAR. The magnitude of IOL rotation was calculated as the absolute value of the error between the actual IOL axis and preoperative IOL insertion axis calculated with the Nidek Toric Calculator For Clinical Trials.

Safety endpoints included the presence, absence, and incidence of adverse events after IOL insertion, and the presence or absence of anticipated adverse events. SAS (Version 9.3, SAS Institute Inc.) was used for statistical analysis. $P<0.05$ was considered statistically significant.

\section{Results}

The study sample was comprised of 64 eyes of 53 patients. Two eyes of one patient were excluded from all analyses due to non-compliance with GCP. One patient died after 6 months examination due to reasons unrelated to cataract surgery. Therefore, the full analysis set for efficacy, included 62 eyes of 52 patients at 6 months postoperatively and 61 eyes of 51 patients at 12 months postoperatively. Table 2 presents patient demographics, baseline examination data and IOL calculation data. The mean age at enrollment was $68.6 \pm$ 9.5 years (Table 2). The mean targeted postoperative refraction was $-1.1 \pm 1.2 \mathrm{D}$ (Table 2).

Table 2 Demographics and preoperative data of patients scheduled to undergo cataract surgery with implantation of the NS60YT intraocular lens. 


\begin{tabular}{|c|c|c|c|c|c|}
\hline Parameter & $\begin{array}{l}\text { All } \\
\text { models }\end{array}$ & NS60YT3 & NS60YT4 & NS60YT5 & NS60YT7 \\
\hline Number of eyes, $\mathrm{n}$ & 62 & 21 & 20 & 15 & 6 \\
\hline Number of patients, $\mathrm{n}$ & 52 & 20 & 20 & 13 & 6 \\
\hline \multicolumn{6}{|l|}{ Age } \\
\hline Mean (years) \pm SD & $\begin{array}{r}68.6 \pm \\
9.5\end{array}$ & $69.1 \pm$ & $68.1 \pm$ & $66.7 \pm$ & $\begin{array}{r}73.2 \pm \\
4.6\end{array}$ \\
\hline Minimum value, maximum value & 42,84 & 54,84 & 48,84 & 42,79 & 66,79 \\
\hline \multicolumn{6}{|l|}{ Sex, $\mathrm{n}$} \\
\hline Male & 27 & 8 & 8 & 9 & 2 \\
\hline Female & 35 & 13 & 12 & 6 & 4 \\
\hline Mean pupil diameter $(\mathrm{mm}) \pm \mathrm{SD}$ & $\begin{array}{r}7.43 \pm \\
0.82\end{array}$ & $\begin{array}{r}7.57 \pm \\
0.62\end{array}$ & $\begin{array}{r}7.25 \pm \\
0.71\end{array}$ & $\begin{array}{r}7.32 \pm \\
0.99\end{array}$ & $\begin{array}{r}7.75 \pm \\
1.25\end{array}$ \\
\hline Mean AL $(\mathrm{mm}) \pm \mathrm{SD}$ & $\begin{array}{r}24.21 \pm \\
1.33\end{array}$ & $\begin{aligned} 24.01 \pm \\
1.35\end{aligned}$ & $\begin{array}{r}23.99 \pm \\
1.47\end{array}$ & $\begin{array}{r}24.77 \pm \\
1.21\end{array}$ & $\begin{array}{r}24.24 \pm \\
0.92\end{array}$ \\
\hline $\begin{array}{l}\text { Mean preoperative corneal } \\
\text { astigmatism (D) } \pm \text { SD }\end{array}$ & $\begin{array}{r}1.73 \pm \\
0.54\end{array}$ & $\begin{array}{r}1.32 \pm \\
0.18\end{array}$ & $\begin{array}{r}1.63 \pm \\
0.24\end{array}$ & $\begin{array}{r}1.95 \pm \\
0.30\end{array}$ & $\begin{array}{r}2.99 \pm \\
0.47\end{array}$ \\
\hline \multicolumn{6}{|l|}{$\begin{array}{l}\text { Preoperative corneal astigmatic axis, } \\
\text { n (\%) }\end{array}$} \\
\hline $\begin{array}{l}\text { WTR astigmatism }\left(0^{\circ} \text { to } 29^{\circ}, 150^{\circ}\right. \\
\left.\text { to } 180^{\circ}\right)\end{array}$ & $29(47)$ & $7(33)$ & $9(45)$ & $10(67)$ & $3(50)$ \\
\hline $\begin{array}{l}\text { OBL astigmatism }\left(30^{\circ} \text { to } 59^{\circ}, 120^{\circ}\right. \\
\left.\text { to } 149^{\circ}\right)\end{array}$ & $1(2)$ & $0(0)$ & $1(5)$ & $0(0)$ & $0(0)$ \\
\hline ATR astigmatism $\left(60^{\circ}\right.$ to $\left.119^{\circ}\right)$ & $32(52)$ & $14(67)$ & $10(50)$ & $5(33)$ & $3(50)$ \\
\hline $\begin{array}{l}\text { Mean postoperative target power (D) } \\
\pm \text { SD }\end{array}$ & $\begin{array}{r}-1.1 \pm \\
1.2 \\
\end{array}$ & $\begin{array}{r}-0.8 \pm \\
1.3 \\
\end{array}$ & $-0.9 \pm 1.0$ & $-1.6 \pm 1.4$ & $-1.3 \pm 1.3$ \\
\hline
\end{tabular}

$\mathrm{ATR}=$ against-the-rule; $\mathrm{AL}=$ axial length $; \mathrm{IOL}=$ intraocular lens; $\mathrm{OBL}=$ oblique; $\mathrm{SD}=$ standard deviation; WTR = with-the-rule

\section{Primary endpoint - uncorrected visual acuity with spherical addition}

Table 3 presents the postoperative UCVA with spherical addition of 0.1 logMAR or better and the $95 \% \mathrm{Cl}$. At 6 months, the primary endpoint was achieved in 90\% (56/62 eyes) for all models, $100 \%$ ( $21 / 21$ eyes), $80 \%$ (16/20 eyes), 93\% (14/15 eyes), and 83\% (5/6 eyes) for NS60YT3, NS60YT4, NS60YT5 and NS60YT7, respectively. At 12 months, $87 \%$ achieved the primary endpoint for all models.

Table 3 Uncorrected visual acuity with spherical addition of 0.1 logMAR or better, 6 and 12 months after cataract surgery with implantation of the NS60YT intraocular lens.

\begin{tabular}{|c|c|c|c|c|c|c|}
\hline \multicolumn{2}{|c|}{ Postoperative } & \multirow{3}{*}{$\begin{array}{r}\text { All } \\
\text { models } \\
62 \\
56 \\
(90)\end{array}$} & \multirow{2}{*}{$\begin{array}{r}\text { NS60YT3 } \\
21 \\
21(100)\end{array}$} & \multirow{3}{*}{$\begin{array}{r}\text { NS60YT4 } \\
20 \\
16(80)\end{array}$} & \multirow{3}{*}{$\begin{array}{r}\text { NS60YT5 } \\
15 \\
14(93)\end{array}$} & \multirow{3}{*}{$\begin{array}{r}\text { NS60YT7 } \\
6(83)\end{array}$} \\
\hline 6 months & Number of eyes, $n$ & & & & & \\
\hline & $\begin{array}{l}\text { UCVA with spherical } \\
\text { addition of } 0.1 \text { logMAR or } \\
\text { better, } \mathrm{n}(\%)\end{array}$ & & $21(100)$ & & & \\
\hline & 95\% CI (\%) & 80,96 & 84,100 & 56,94 & 68,100 & 36,100 \\
\hline \multirow[t]{3}{*}{12 months } & Number of & 61 & 21 & 20 & 14 & 6 \\
\hline & $\begin{array}{l}\text { UCVA with spherical } \\
\text { addition of } 0.1 \text { logMAR or } \\
\text { better, } n(\%)\end{array}$ & $\begin{array}{r}53 \\
(87)\end{array}$ & $18(86)$ & $18(90)$ & $12(86)$ & $5(83)$ \\
\hline & 95\% CI (\%) & 76,94 & 64,97 & 68,99 & 57,98 & 36,100 \\
\hline
\end{tabular}


$\mathrm{CI}=$ confidence interval; $\mathrm{UCVA}=$ uncorrected visual acuity

\section{Other efficacy parameters and safety parameters}

\section{Visual acuity}

Table 4 presents the UCVA, UCVA with spherical addition, sphere-corrected VA, BCVA and subjective cylindrical power up to 12 months postoperatively. UCVA with spherical addition, sphere-corrected VA and BCVA remained stable until 12 months postoperatively after 1 month postoperatively (Table 4). At 12 months postoperatively, the residual subjective cylindrical power ( the dioptric power determined during subjective refraction) was less than $0.50 \mathrm{D}$ in $59 \%$ (36/61 eyes) and less than $1.00 \mathrm{D}$ in $89 \%$ (54/61 eyes) for all models combined.

Table 4 Mean efficacy parameters for eyes that underwent cataract surgery with NS60YT intraocular lens implantation.

\begin{tabular}{|c|c|c|c|c|c|c|}
\hline & 1 day & 1 week & 1 month & 3 months & 6 months & $\begin{array}{l}12 \\
\text { months }\end{array}$ \\
\hline UCVA (logMAR) & $\begin{array}{r}0.29 \pm \\
0.38\end{array}$ & $\begin{array}{r}0.28 \pm \\
0.40\end{array}$ & $\begin{array}{r}0.27 \pm \\
0.42\end{array}$ & $\begin{array}{r}0.28 \pm \\
0.43\end{array}$ & $\begin{array}{r}0.29 \pm \\
0.45\end{array}$ & $\begin{array}{r}0.28 \pm \\
0.42\end{array}$ \\
\hline $\begin{array}{l}\text { UCVA with spherical addition } \\
\text { (logMAR) }\end{array}$ & $\begin{array}{r}0.08 \pm \\
0.19\end{array}$ & $\begin{array}{r}0.04 \pm \\
0.17\end{array}$ & $\begin{array}{r}0.03 \pm \\
0.19\end{array}$ & $\begin{array}{r}0.03 \pm \\
0.16\end{array}$ & $\begin{array}{r}0.02 \pm \\
0.17\end{array}$ & $\begin{array}{r}0.00 \pm \\
0.11\end{array}$ \\
\hline $\begin{array}{l}\text { Sphere-corrected } \\
\text { (logMAR) }\end{array}$ & $\begin{aligned}-0.01 \pm \\
0.11\end{aligned}$ & $\begin{array}{r}-0.04 \pm \\
0.09\end{array}$ & $\begin{array}{r}-0.05 \pm \\
0.07\end{array}$ & $\begin{array}{r}-0.05 \pm \\
0.07\end{array}$ & $\begin{array}{r}-0.05 \pm \\
0.07\end{array}$ & $\begin{array}{r}-0.05 \pm \\
0.07\end{array}$ \\
\hline BCVA (logMAR) & $\begin{array}{r}-0.05 \pm \\
0.09\end{array}$ & $\begin{array}{r}-0.08 \pm \\
0.07\end{array}$ & $\begin{aligned}-0.09 \pm \\
0.05\end{aligned}$ & $\begin{aligned}-0.10 \pm \\
0.05\end{aligned}$ & $\begin{aligned}-0.10 \pm \\
0.06\end{aligned}$ & $\begin{array}{r}-0.10 \pm \\
0.06\end{array}$ \\
\hline $\begin{array}{l}\text { Subjective cylindrical power } \\
\text { (D) }\end{array}$ & $\begin{array}{r}0.54 \pm \\
0.61 \\
\end{array}$ & $\begin{array}{r}0.53 \pm \\
0.56 \\
\end{array}$ & $\begin{array}{r}0.55 \pm \\
0.46 \\
\end{array}$ & $\begin{array}{r}0.61 \pm \\
0.45 \\
\end{array}$ & $\begin{array}{r}0.58 \pm \\
0.49 \\
\end{array}$ & $\begin{array}{r}0.55 \pm \\
0.47 \\
\end{array}$ \\
\hline
\end{tabular}

$\mathrm{BCVA}=$ best corrected visual acuity; IOL = intraocular lens; logMAR = logarithm of the minimum angle of resolution; UCVA = uncorrected visual acuity; VA = visual acuity

Fig. 2 presents the double angle polar plots. There were no remarkable changes observed between the preoperative corneal astigmatism (Fig. 2a) and the 12 months postoperative corneal astigmatism (Fig. 2b). However, in eyes with subjective cylinder at 12 months postoperatively, the cylinder components tended towards against-the-rule (ATR) astigmatism (Fig. 2c).

\section{Intraocular lens rotation (including additional analysis)}

Fig. 3 presents the distribution of the rotation (absolute value) at 12 months compared to the axis of IOL insertion. A deviation less than $10^{\circ}$ between the IOL axis and the insertion axis was noted in $89 \%$ (54/61 eyes) 
of all models. No cases required repositioning surgery due to postoperative IOL rotation.

Fig. 4 plots the postoperative changes in rotation relative to the insertion axis. The magnitude of rotation in all models was $5.5 \pm 3.8^{\circ}$ at 1 day, $5.6 \pm 4.0^{\circ}$ at 1 week, $5.1 \pm 4.2^{\circ}$ at 1 month, $5.4 \pm 4.2^{\circ}$ at 3 months, $5.0 \pm 4.4^{\circ}$ at 6 months, and $5.3 \pm 4.3^{\circ}$ at 12 months. Additional analysis indicated that the magnitude of rotation the day after surgery was $5.5^{\circ}$, and the mean rotation between each examination after day 1 was $2.5^{\circ}$ or lower (Table 5). A rotation of $5.0^{\circ}$ or more occurred in $52 \%$ by day 1 , however, a rotation of $5.0^{\circ}$ or more after day 1 was 7 to $13 \%$ for each period (Table 5). At 12 months postoperatively, the IOL rotated clockwise in $61 \%$ (37/61) of eyes, counterclockwise in 31\% (19/61) of eyes, and the IOL did not rotate in $8 \%$ (5/61) of eyes. The direction of rotation and the preoperative corneal cylinder axis were not statistically associated (Fisher's exact test, $P=$ 0.781).

Table 5 Rotational stability of the NS60YT intraocular lens.

\begin{tabular}{|c|c|c|c|c|c|}
\hline \multirow[t]{2}{*}{ ostoperative } & \multirow{2}{*}{$\begin{array}{l}\text { Number of } \\
\text { eyes, } \mathrm{n}\end{array}$} & \multirow{2}{*}{$\begin{array}{l}\text { Rotation amount } \\
\text { (absolute value) } \pm \mathrm{SD}\left({ }^{\circ}\right)\end{array}$} & \multicolumn{3}{|c|}{ Lens rotation amount, $\mathrm{n}(\%)$} \\
\hline & & & $\begin{array}{l}\text { Less } \\
\text { than } \\
5.0^{\circ}\end{array}$ & $\begin{array}{l}5.0^{\circ} \text { or more and } \\
\text { less than } 10.0^{\circ}\end{array}$ & $\begin{array}{l}10.0^{\circ} \text { or } \\
\text { more }\end{array}$ \\
\hline day & 61 & $5.5 \pm 3.8$ & $29(48)$ & $22(36)$ & $10(16)$ \\
\hline $\begin{array}{l}\text { L day to } 1 \\
\text { Neek }\end{array}$ & 61 & $2.5 \pm 2.7$ & $55(90)$ & $4(7)$ & $2(3 \square$ \\
\hline $\begin{array}{l}\text { week to } 1 \\
\text { nonth }\end{array}$ & 61 & $2.2 \pm 1.7$ & $55(90)$ & $6(10)$ & $0(0)$ \\
\hline $\begin{array}{l}\text { month to } 3 \\
\text { nonths }\end{array}$ & 61 & $2.0 \pm 1.8$ & $56(92)$ & $5(8)$ & $0(0)$ \\
\hline $\begin{array}{l}3 \text { months to } 6 \\
\text { nonths }\end{array}$ & 61 & $2.1 \pm 2.0$ & $53(87)$ & $8(13)$ & $0(0)$ \\
\hline $\begin{array}{l}\text { i months to } \\
2 \text { months }\end{array}$ & 61 & $1.9 \pm 1.5$ & $57(93)$ & $4(7)$ & $0(0)$ \\
\hline $\begin{array}{l}\text { day to } 12 \\
\text { nonths }\end{array}$ & 61 & $3.1 \pm 2.9$ & $47(77)$ & $11(18)$ & $3(5)$ \\
\hline
\end{tabular}

$\mathrm{SD}=$ standard deviation

\section{Patient satisfaction}

A questionnaire at 6 months queried patient satisfaction. For all models, the results were "very satisfied" $52 \%$ (32/62 eyes), "satisfied” 40\% (25/62 eyes), "neither satisfied nor dissatisfied” 3\% (2/62 eyes), "dissatisfied” $5 \%$ (3/62 eyes), and "very dissatisfied" 0\% (0/62 eyes). Thus, "very satisfied" and "satisfied" accounted for $92 \%$ of eyes.

\section{Safety}

Postoperative adverse events where a causal relationship could not be ruled out included 4 eyes (6\%) with mild posterior capsule opacification. Anticipated adverse events (defined separately at the beginning of the study) developed in 6 eyes of 5 patients. These included 2 eyes (3\%) with secondary cataract (requiring posterior capsulotomy) and 4 eyes (6\%) with increased IOP. One patient died during the course of the study due to multiple organ failure which was a non-ocular adverse event and had no causal relationship to cataract surgery or IOL implantation. 


\section{Discussion}

This prospective evaluation of a new toric IOL (NS60YT) indicated the majority of eyes had excellent vision after cataract surgery. For example, BCVA at 12 months postoperatively was $-0.10 \pm 0.06$ logMAR. The primary endpoint of the study was UCVA with spherical addition for this Japanese population. This index was used as the primary endpoint taking into consideration the tendency of lens selection in Japan. Japanese cataract patients tend to prefer some nearsightedness instead of emmetropia postoperatively. Using an UCVA with spherical addition as the primary endpoint enabled comparison with the published literature on toric IOLs targeting emmetropia despite targeting postoperative myopia (in the current study).

At 6 months postoperatively, 90\% (56/62 eyes) of all eyes achieved UCVA with spherical addition of 0.1 logMAR or better. The lower limit ( $80 \%)$ of the $95 \% \mathrm{Cl}$ exceeded the expected response rate of $70 \%$, which was the basis for determining the number of cases. This outcome indicates, that patients achieved equivalent or better postoperative visual acuity with the NS60YT in comparison with commercially available toric IOLs as the historical controls.

In contrast to the UCVA with spherical addition, sphere-corrected VA is the visual acuity obtained by further correcting the postoperative spherical refractive error only. In addition, the BCVA is the best visual acuity obtained by further correcting the residual postoperative cylindrical power from the sphere-corrected VA. This means that the difference between the UCVA with spherical addition and the sphere-corrected VA is the spherical refractive error with respect to the target refractive power. Additionally, the difference between the sphere-corrected VA and the BCVA is the cylindrical refractive error. Twelve months after surgery, the outcomes of the current study indicate a sphere-corrected VA of less than 0.1 logMAR in only one eye (2\%), and 0.1 logMAR or better in the other 60 eyes (98\%). This outcome indicates excellent cylinder correction with the NS60YT.

Vector analysis indicated that the postoperative subjective cylinder had a distribution toward ATR astigmatism. This trend is similar to the outcomes of wavefront analysis reported by Ninomiya et al [11]. The primary cause of ATR astigmatism after surgery could be due to the effect of posterior corneal astigmatism.

As this study was designed in 2014 , the protocol did not incorporate the effect of posterior corneal curvature. The current study used only the anterior corneal surface to evaluate corneal astigmatism, and the Nidek Toric Calculator For Clinical Trials did not consider the posterior corneal astigmatism for lens selection. Koch et al [12] have reported that posterior corneal astigmatism causes overcorrection of with-the-rule (WTR) astigmatism and decreases the correction of ATR astigmatism when the lens selection is based on the anterior corneal astigmatism only. Hence, our outcomes are consistent with Koch et al's observations [13]. Savini et al have published nomograms for selecting the IOL power when only the anterior corneal astigmatism is used. For preoperative WTR astigmatism, residual astigmatism is calculated based on the result from subtracting $0.59 \mathrm{D}$ to $0.70 \mathrm{D}$ from the predicted postoperative corneal astigmatism [14]. For preoperative ATR astigmatism, residual astigmatism is calculated based on the result of adding $0.32 \mathrm{D}$ to $0.70 \mathrm{D}$ to the predicted postoperative corneal astigmatism [14]. The current version of the Nidek Toric Calculator includes the Baylor nomogram to compensate for the posterior surface power when only anterior corneal surface data are used $[12,13]$. 
Accurate cylinder axis marking and rotational stability in the eye are important because the IOL correction of astigmatism decreases by $3.3 \%$ for an axial misalignment of $1^{\circ}$, and toric IOL implantation is completely ineffective when the misalignment is $30^{\circ}$ or greater [15]. The outcomes of the current study indicate the NS60YT has good rotational stability. For example, the mean IOL rotation at 6 months was $5.0 \pm 4.4^{\circ}$ for all models combined which is well within the range reported for other IOLs. Previous studies have reported rotation of single-piece toric IOLs between the intended axis and the observed axis from $2^{\circ}$ to $9^{\circ}$ at 6 months postoperatively $[9,16-20]$. Additionally, in the current study, the magnitude of rotation ranged from $1.9^{\circ}$ to $2.5^{\circ}$ between each postoperative examination from 1 day to 12 months and the mean rotation was $3.1 \pm 2.9^{\circ}$. The tendency to rotate early in the postoperative period and then stabilize was similar to the previous literature on existing single-piece toric IOLs [21-23].

The anchor wing-haptic design contributes to the stability of the NS60YT toric IOL. The $90^{\circ}$ orientation of the anchor wing-haptic design makes it difficult to generate a force in the rotational direction from compression due to the pressure from capsular contraction. Additionally, the width between the haptic shoulders is based on an average capsular diameter. The design geometry allows a secure fit within the capsular bag using the shoulders to stabilize the IOL without relying on the overall haptics ('arms') of the IOL.

Table 6 Cases with rotation of $10^{\circ}$ or greater at 12 months postoperatively.

Table 6 presents data on seven cases with a rotation of $10^{\circ}$ or greater at 12 months postoperatively relative to the IOL insertion axis. Five cases (except Cases 3 and 4 ) rotated $10^{\circ}$ or more at 1 day. In Case 4 , a rotation of $10^{\circ}$ or more was observed initially at 1 month. This case had an incomplete closed capsulorhexis with 2 tears. Perhaps postoperative healing and suboptimal capsular contraction due to the tears may have played a role in the rotation. Case 3 presented with a rotation of $10^{\circ}$ or more initially at 12 months. The subsequent rotations were as follows: $-4^{\circ}$ at 1 week; $-2^{\circ}$ at 1 month; $-9^{\circ}$ at 3 months; $-9^{\circ}$ at 6 months; and $-13^{\circ}$ at 12 months. We are at a loss to explain the IOL rotation between visits. However we can rule out abnormal head positioning as experienced technicians, familiar with the equipment ensured the patient's head was in correct position prior to acquiring images. Although abnormal head position may have been missed at one visit, it would be highly unlikely in consecutive visits with the same patient. Additionally, the observation that the majority of patients were not symptomatic concurs with the low magnitude of rotation reported in the current study and indicates that relatively good image acquisition techniques and accurate measurements were used in the current study.

The cause of rotation in this case is unknown, however, the patient was asymptomatic and there were no postoperative sequelae. In these cases, the UCVA with spherical addition was $0.1 \log$ MAR or better with Cases 2 and 4 excluded, and the sphere corrected VA was 0.05 logMAR or better with Case 2 excluded. Patient satisfaction with their vision remained high in all cases with a rotation of $10^{\circ}$ or more.

This study evaluated the difference of the IOL axis at each postoperative examination relative to the insertion axis. Therefore, the evaluation included fixed axis deviation of the IOL intraoperatively and the rotation from the early postoperative phase onwards. To verify the rotation from the insertion axis more accurately, the amount of rotation immediately after insertion of the IOL needs to be evaluated. 


\begin{tabular}{|c|c|c|c|c|c|c|c|}
\hline & Case 1 & Case 2 & Case 3 & Case 4 & Case 5 & Case 6 & Case 7 \\
\hline $\begin{array}{l}\text { Amount of } \\
\text { rotation }\left({ }^{\circ}\right)^{*}\end{array}$ & 15 & -16 & -13 & 10 & -18 & 18 & -12 \\
\hline $\begin{array}{l}\text { Expected IOL } \\
\text { axis angle }\left({ }^{\circ}\right)\end{array}$ & 4 & 10 & 95 & 177 & 87 & 94 & 161 \\
\hline IOL axis angle $\left(^{\circ}\right)$ & 19 & 174 & 82 & 7 & 69 & 112 & 149 \\
\hline $\begin{array}{l}\text { When the } \\
\text { rotation } \\
\text { exceeded } 10^{\circ}\end{array}$ & 1 day & 1 day & $\begin{array}{l}12 \\
\text { months }\end{array}$ & 1 month & 1 day & 1 day & 1 day \\
\hline Model & NS60YT7 & NS60YT3 & NS60YT5 & NS60YT3 & NS60YT3 & NS60YT3 & NS60YT3 \\
\hline $\begin{array}{l}\text { Spherical power } \\
\text { (D) }\end{array}$ & 17.0 & 19.0 & 21.5 & 20.0 & 21.5 & 18.0 & 20.0 \\
\hline $\mathrm{AL}(\mathrm{mm})$ & 25.50 & 25.00 & 23.61 & 24.85 & 23.13 & 25.17 & 25.28 \\
\hline Age (y) & 72 & 63 & 45 & 72 & 58 & 59 & 70 \\
\hline $\begin{array}{l}\text { Anterior } \\
\text { capsulotomy }\end{array}$ & CCC & CCC & $\mathrm{CCC}$ & $\begin{array}{l}\text { CCC with } \\
\text { 2-tear }\end{array}$ & $\mathrm{CCC}$ & $\mathrm{CCC}$ & $\mathrm{CCC}$ \\
\hline $\begin{array}{l}\text { UCVA with } \\
\text { spherical } \\
\text { addition(logMAR) }\end{array}$ & -0.08 & 0.22 & -0.18 & 0.15 & -0.08 & -0.08 & 0.05 \\
\hline $\begin{array}{l}\text { Sphere-corrected } \\
\text { VA(logMAR) }\end{array}$ & -0.08 & 0.22 & -0.18 & 0.05 & -0.08 & -0.18 & 0.00 \\
\hline $\begin{array}{l}\text { BCVA(logMAR) } \\
\text { (Cylinder } \\
\text { correction } \\
\text { amount) }\end{array}$ & $\begin{array}{l}-0.18 \\
(-1.75 \mathrm{D})\end{array}$ & $\begin{array}{l}0.05 \\
(-1.00 \mathrm{D})\end{array}$ & $\begin{array}{l}-0.18 \\
(-0.50 \mathrm{D})\end{array}$ & $\begin{array}{l}0.00 \\
(-0.25 \mathrm{D})\end{array}$ & $\begin{array}{l}-0.08 \\
(-1.50 \mathrm{D})\end{array}$ & $\begin{array}{l}-0.18 \\
(-0.25 \mathrm{D})\end{array}$ & $\begin{array}{l}-0.08 \\
(-0.75 \mathrm{D})\end{array}$ \\
\hline
\end{tabular}

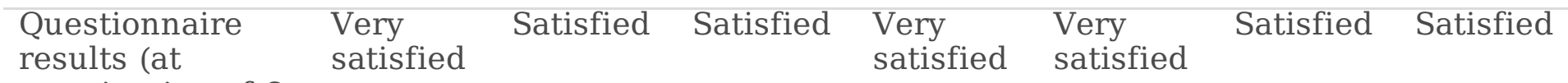
examination of 6 months)

$\mathrm{AL}=$ axial length; BCVA = best corrected visual acuity; CCC = continuous curvilinear capsulorhexis; IOL = intraocular lens; UCVA = uncorrected visual acuity; VA = visual acuity

$*$ Rotation amount: plus $=$ counterclockwise, minus $=$ clockwise

\section{Conclusions}

In summary, the outcomes of this study indicate that a new toric IOL with anchor-wing haptics is safe and effective for implantation during cataract surgery. Axis rotation was very low in the majority of cases and clinically insignificant and repositioning of the IOL was not warranted in any patient. Implantation of this toric IOL provides satisfactory postoperative visual acuity and good patient satisfaction

\section{Abbreviations}

ATR: Against-the-rule
AL: Axial length

BCVA: Best corrected visual acuity

CCC: Continuous curvilinear capsulorhexis

Cl: Confidence interval 

D: Diopter

GCP: Good clinical practice

IOL: Intraocular lens

IOP: Intraocular pressure

LogMAR = Logarithm of the minimum angle of resolution;

OBL: Oblique

SD: Standard deviation

UCVA: Uncorrected visual acuity

VA: Visual acuity

WTR: With-the-rule

\section{Declarations}

\section{Ethics approval and consent to participate}

This study adhered to the principles of the Declaration of Helsinki. This study was approved by the Jikei University Hospital Institutional Review Board for Medical Devices, the Sugita Eye Hospital Institutional Review Board, and the Joint Institutional Review Board of the hospitals. Written informed consent was obtained from all individual participants included in the study.

\section{Consent for publication}

Not applicable.

\section{Availability of data and materials}

The datasets used and analyzed during the current study are available from the corresponding author on reasonable request.

\section{Competing interests}

Dr. Sugita, Ogawa, Ichikawa, Okita, Nakano, and Tsuneoka report grants and Dr Negishi report personal fees from NIDEK CO., LTD., during the conduct of the study;. Dr. Sugita reports grants and personal fees from Alcon Japan Ltd., personal fees and non-financial support from Santen Pharmaceutical Co., Ltd., non-financial support from HOYA Corporation, personal fees from Kowa Co., Ltd., grants and personal fees from Senjyu Pharmaceutical Co., Ltd., personal fees from Carl Zeiss Meditec AG, personal fees from Bayer AG, personal fees from Pfizer Inc., personal fees from Nikon Corporation, outside the submitted work; . Dr. Ichikawa reports grants and personal fees from Alcon, grants and personal fees from ZEISS, grants and personal fees from 
STAAR, personal fees from HOYA, personal fees from SANTEN, personal fees from KY CenterVue, personal fees from Igaku shoin, personal fees from Kowa, personal fees from JFC, personal fees from Novartis, outside the submitted work; . Dr. Negishi reports grants from Fuji Xerox Co, grants from Hitachi Automotive Systems, Ltd., grants from Universal View Co., Ltd., grants and personal fees from Alcon Japan Ltd. , grants and personal fees from Santen Pharmaceutical, grants and personal fees from HOYA Corporation, grants and personal fees from AMO Japan K.K., grants from Kowa Company, grants from Kowa Pharmaceutical Company Ltd. , grants from Tomey Corporation, personal fees from Senju Pharmaceutical , personal fees from Otsuka Pharmaceutical, personal fees from NIDEK Co., Ltd., personal fees from Carl Zeiss Meditec AG, outside the submitted work; Dr. Negishi has a patent (PCT/JP2015/65997, PCT/JP2016/085903) for potential products for myopia suppression pending to Tsubota Laboratory Inc.

\section{Funding}

The study sponsor, NIDEK CO., LTD. (Aichi, Japan) provided funding to each investigator's academic institution or private practice to conduct the clinical trial and provided personal fees to a medical expert. The study devices were provided by the sponsor.

\section{Authors' contributions}

$\mathrm{KN}$ and $\mathrm{HT}$ contributed to the study conception and design. Material preparation, data collection and analysis were performed by IS, TO, KI, TO, TN, and HT. The first draft of the manuscript was written by IS and all authors commented on previous versions of the manuscript. All authors read and approved the final manuscript, and agreed both to be personally accountable for the author's own contributions and to ensure that questions related to the accuracy or integrity of any part of the work, even ones in which the author was not personally involved, are appropriately investigated, resolved, and the resolution documented in the literature.

\section{Acknowledgements}

Not applicable

\section{References}

1. Ferrer-Blasco T, Montés-Micó R, Peixoto-de-Matos SC, González-Méijome JM, Cerviño A. Prevalence of corneal astigmatism before cataract surgery. J Cataract Refract Surg. 2009;35:70-75

2. Hoffer KJ. Biometry of 7,500 cataractous eyes. Am J Ophthalmol.1980;90:360-368

3. Ninn-Pedersen K, Stenevi U, Ehinger B. Cataract patients in a defined Swedish population 1986-1990. II. Preoperative observations. Acta Ophthalmol. 1994;72:10-15.

4. Hoffmann PC, Hütz WW. Analysis of biometry and prevalence data for corneal astigmatism in 23,239 eyes. J Cataract Refract Surg. 2010;36:1479-1485.

5. Behndig A, Montan P, Stenevi U, Kugelberg M, Zetterström C, Lundström M. Aiming for emmetropia after cataract surgery: Swedish National Cataract Register study. J Cataract Refract Surg. 2012;38:1181-6. 
6. Wilkins MR, Allan B, Rubin G. Spectacle use after routine cataract surgery. Br J Ophthalmol. 2009;93:1307-12.

7. Kessel L, Andresen J, Tendal B, Erngaard D, Flesner P, Hjortdal J. Toric Intraocular Lenses in the Correction of Astigmatism During Cataract Surgery: A Systematic Review and Meta-analysis. Ophthalmology. 2016;123:275-86.

8. Alcon Research Ltd. Summary of safety and effectiveness data_ACRYSOF® Single-Piece Posterior Chamber Intraocular Lenses With Toric Optic.2005. https://www.accessdata.fda.gov/cdrh_docs/pdf/P930014S015b.pdf. Accessed October 27, 2019.

9. Ahmed II, Rocha G, Slomovic AR, Climenhaga H, Gohill J, Grégoire A, Ma J; Canadian Toric Study Group. Visual function and patient experience after bilateral implantation of toric intraocular lenses. J Cataract Refract Surg. 2010;36:609-616

10. Bauer NJ, de Vries NE, Webers CA, Hendrikse F, Nuijts RM. Astigmatism management in cataract surgery with the AcrySof toric intraocular lens. J Cataract Refract Surg. 2008;34:1483-1488

11. Ninomiya Y, Kojima Y, Maeda N. [Assessment of astigmatism correction in cataract surgery with toric intraocular lens using vector analysis]. Rinsho Ganka. 2012;66:1147-1152

12. Koch DD, Ali SF, Weikert MP, Shirayama M, Jenkins R, Wang L. Contribution of posterior corneal astigmatism to total corneal astigmatism. J Cataract Refract Surg. 2012;38:2080-2087.

13. Koch DD, Jenkins RB, Weikert MP, Yeu E, Wang L. Correcting astigmatism with toric intraocular lenses: Effect of posterior corneal astigmatism. J Cataract Refract Surg. 2013;39:1803-1809

14. Savini G, Næser K. An analysis of the factors influencing the residual refractive astigmatism after cataract surgery with toric intraocular lenses. Invest Ophthalmol Vis Sci. 2015;56:827-835

15. Shimizu K, Misawa A, Suzuki Y. Toric intraocular lenses: correcting astigmatism while controlling axis shift. J Cataract Refract Surg. 1994;20:523-526

16. Koshy JJ, Nishi Y, Hirnschall N, et al. Rotational stability of a single-piece toric acrylic intraocular lens. J Cataract Refract Surg. 2010;36:1665-1670. doi:10.1016/j.jcrs.2010.05.018

17. Alió JL, Piñero DP, Tomás J, Alesón A. Vector analysis of astigmatic changes after cataract surgery with toric intraocular lens implantation. J Cataract Refract Surg. 2011;37:1038-1049.

doi:10.1016/j.jcrs.2010.12.053

18. Visser N, Ruíz-Mesa R, Pastor F, Bauer NJ, Nuijts RM, Montés-Micó R. Cataract surgery with toric intraocular lens implantation in patients with high corneal astigmatism. J Cataract Refract Surg. 2011;37:1403-1410. doi:10.1016/j.jcrs.2011.03.034

19. Visser N, Beckers HJM, Bauer NJC, et al. Toric vs Aspherical Control Intraocular Lenses in Patients With Cataract and Corneal Astigmatism: A Randomized Clinical Trial. JAMA Ophthalmol. 2014;132:14621468. doi:10.1001/jamaophthalmol.2014.3602

20. Hirnschall N, Gangwani V, Crnej A, Koshy J, Maurino V, Findl O. Correction of moderate corneal astigmatism during cataract surgery: toric intraocular lens versus peripheral corneal relaxing incisions. J Cataract Refract Surg. 2014;40:354-361. doi:10.1016/j.jcrs.2013.08.049

21. Weinand F, Jung A, Stein A, Pfützner A, Becker R, Pavlovic S. Rotational stability of a single-piece hydrophobic acrylic intraocular lens: new method for high-precision rotation control. J Cataract Refract 
Surg. 2007;33:800-803. doi:10.1016/j.jcrs.2007.01.030

22. Hirnschall N, Maedel S, Weber M, Findl O. Rotational stability of a single-piece toric acrylic intraocular lens: a pilot study. Am J Ophthalmol. 2014;157(2):405-411.e1. doi:10.1016/j.ajo.2013.09.032

23. Waltz KL, Featherstone K, Tsai L, Trentacost D. Clinical outcomes of TECNIS toric intraocular lens implantation after cataract removal in patients with corneal astigmatism. Ophthalmology. 2015;122(1):39-47. doi:10.1016/j.ophtha.2014.06.027

\section{Figures}

\section{$\phi 13.0 \mathrm{~mm}$}
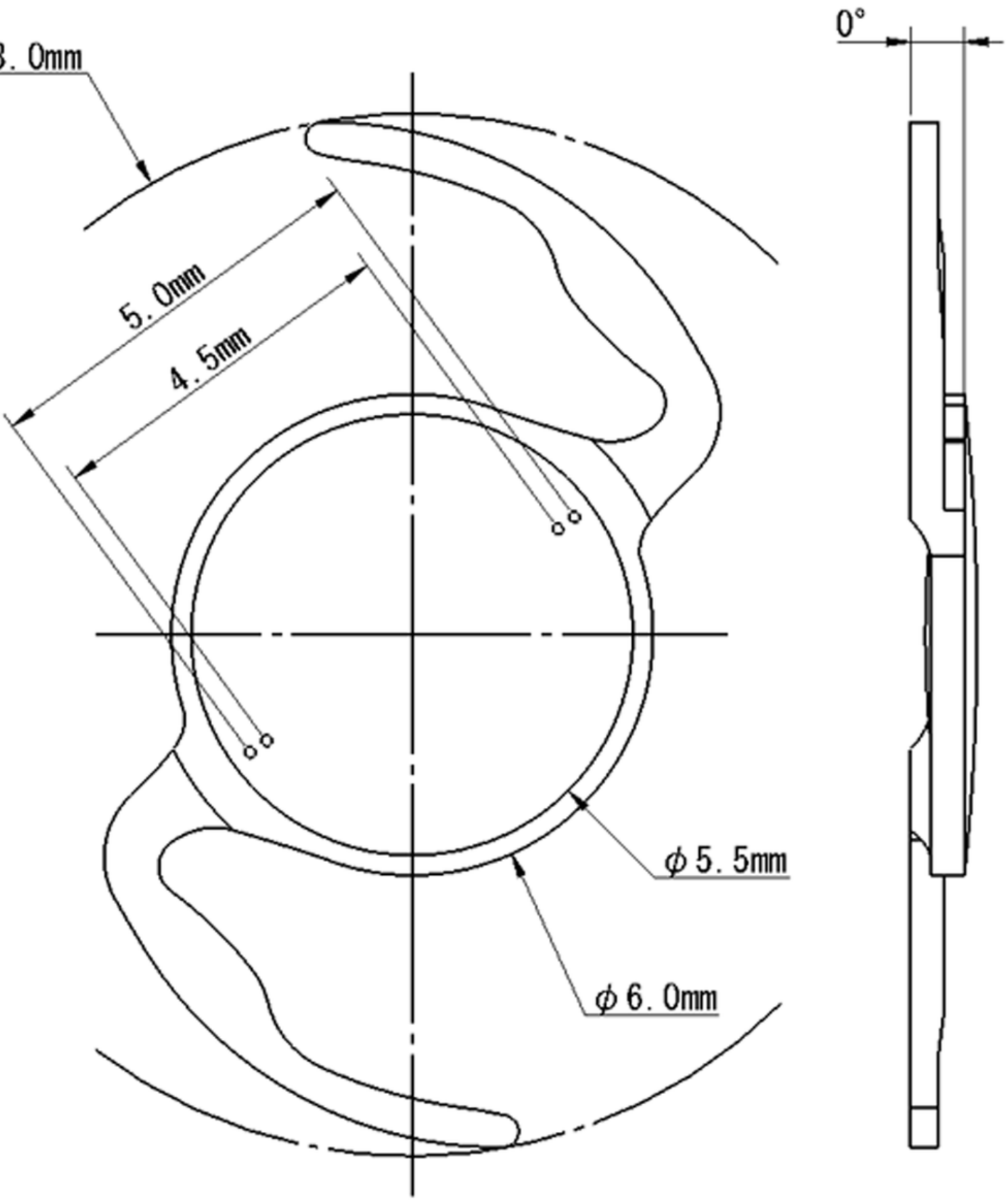


\section{Figure 1}

Design specifications of the NS60YT intraocular lens The shape of anchor-wing haptics contributes to intraocular lens stability because it is difficult to generate a force in the rotational direction by compression. Additionally, the contact area in the capsule is large which contributes to good fixational stability.

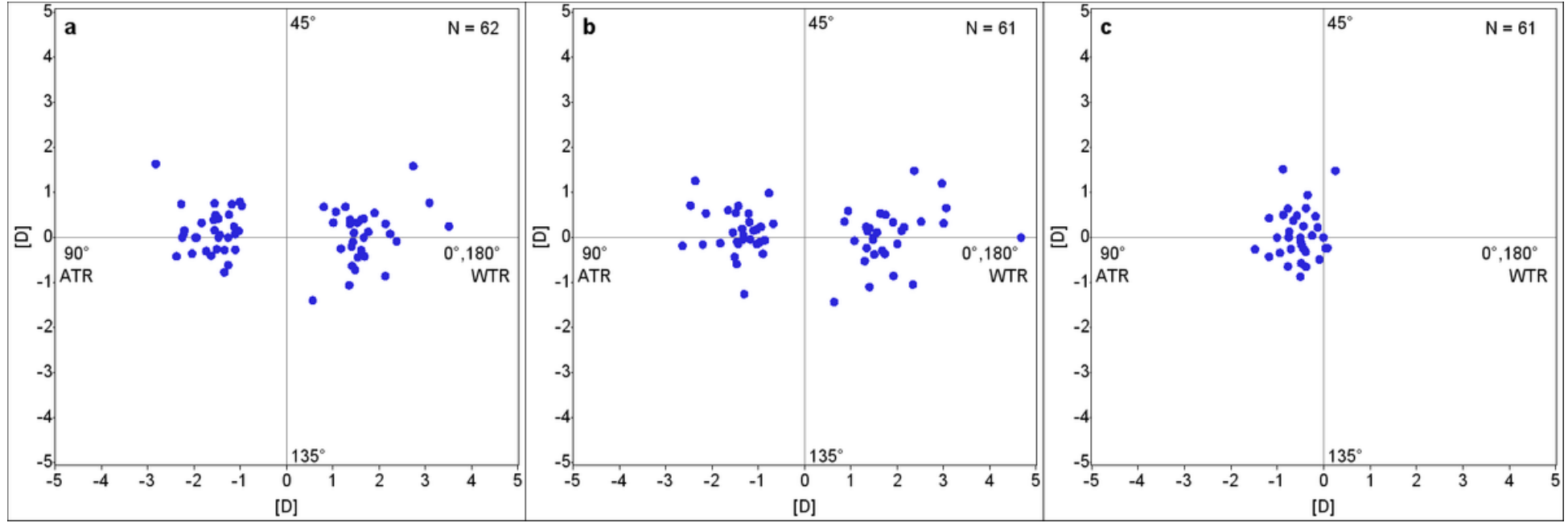

\section{Figure 2}

Corneal astigmatism and postoperative subjective cylinder components (ATR = against-the-rule; WTR = withthe-rule) (a) Preoperative corneal astigmatism (b) 12 months postoperative corneal astigmatism (c) 12 months postoperative subjective cylinder components 


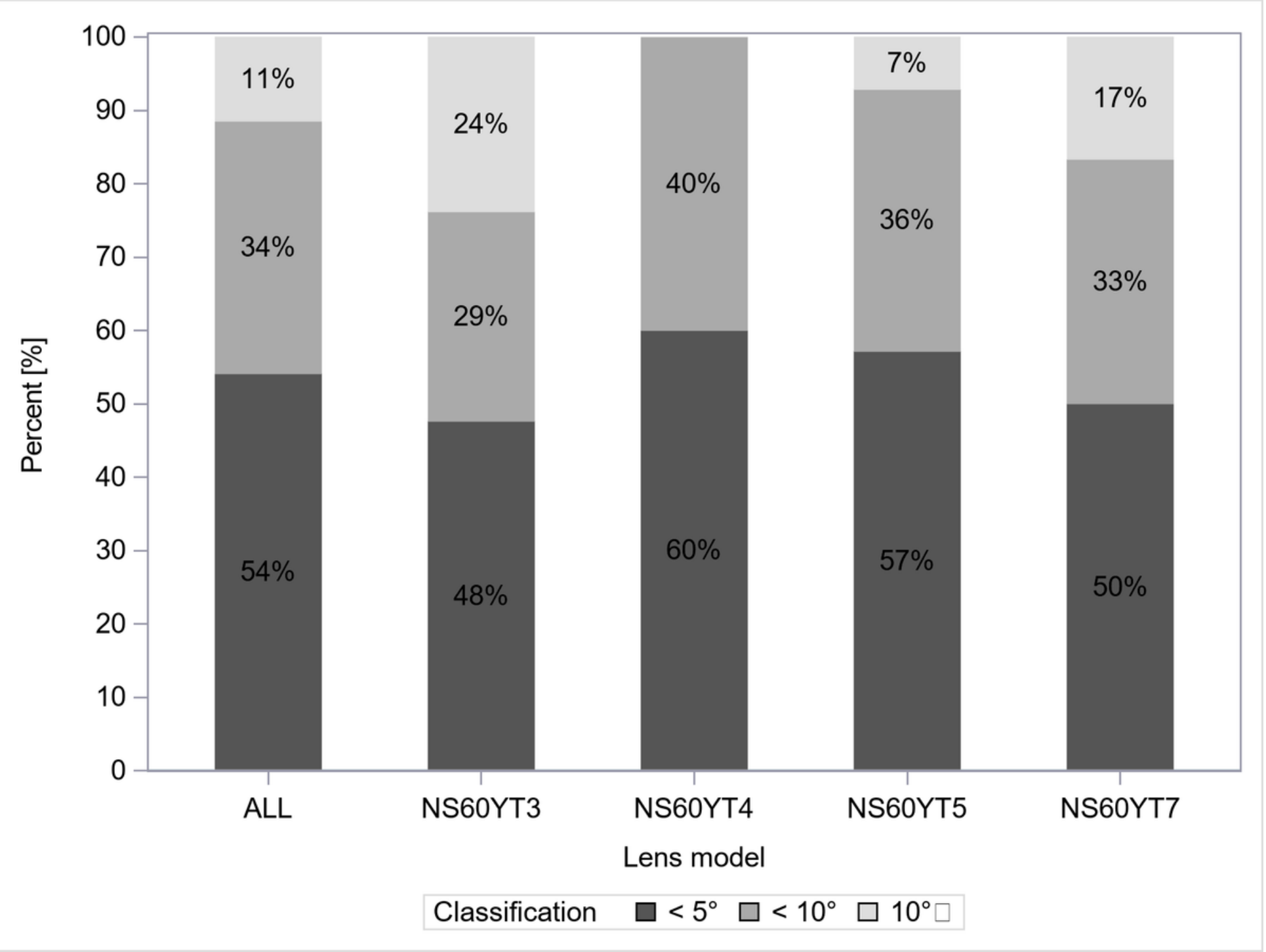

Figure 3

Distribution of intraocular lens rotation at 12 months after surgery 


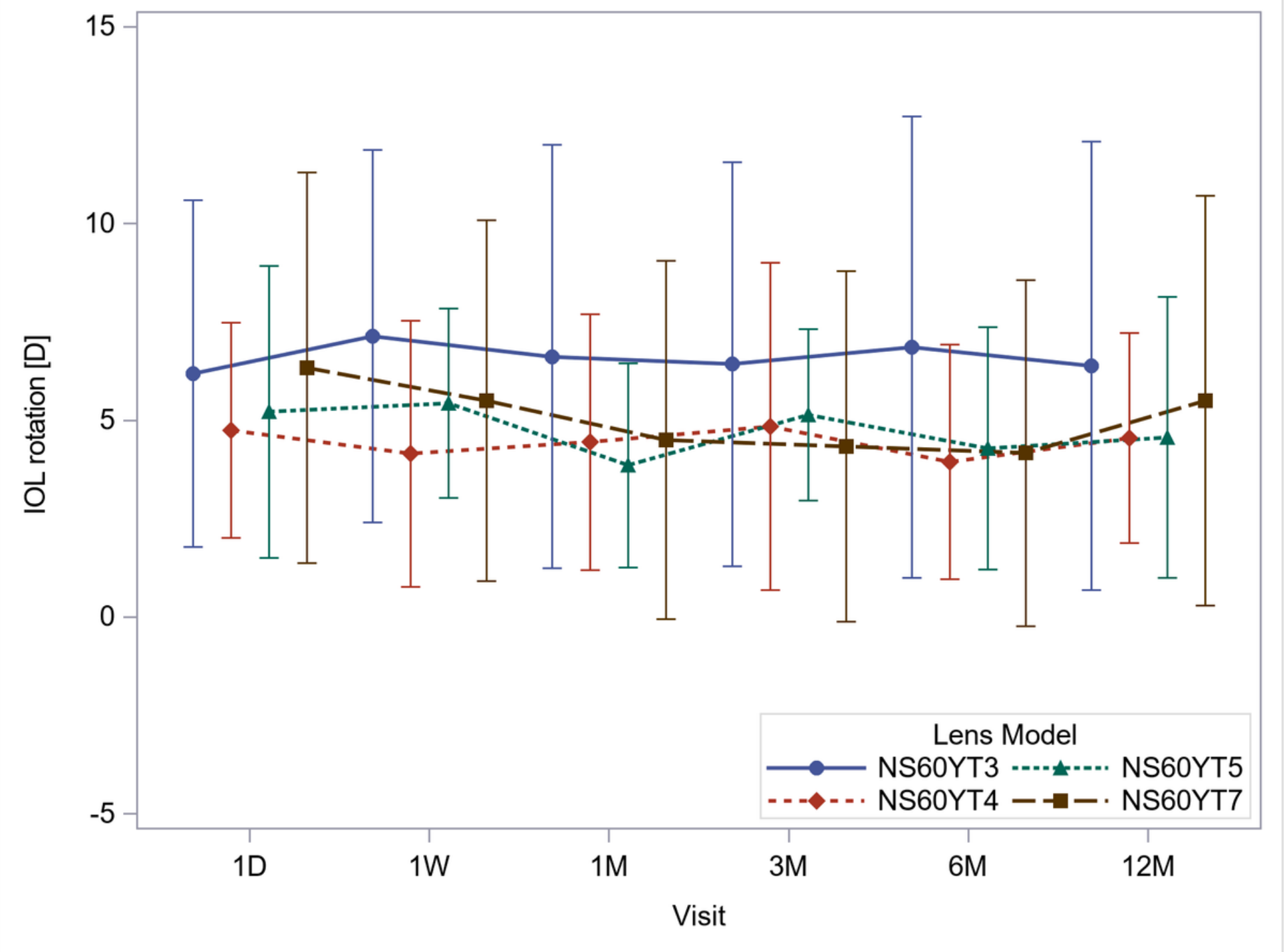

Figure 4

Rotation over time of the intraocular lens axis from the expected insertion axis

\section{Supplementary Files}

This is a list of supplementary files associated with this preprint. Click to download.

- CONSORT2010Checklist.doc 